\title{
Updated Epidemiological Aspects and outcome of Meningitis Cases at Abbassia Fever Hospital during the Period 2006-2017
}

\author{
Amany Ahmed Ibrahim ${ }^{1}$, Sara Mahmoud Abdel Hakam', \\ Azza Mohammed Hassan Ahmed², Amr Mahmoud Hussein ${ }^{3}$, \\ Amira Mahmoud Al Balakosy ${ }^{1}$ \\ ${ }^{1}$ Department of Tropical Medicine, Faculty of Medicine, Ain Shams University, Egypt. \\ ${ }^{2}$ Department of Community, Environmental and Occupational Medicine, Faculty of \\ Medicine, Ain Shams University, Egypt. \\ ${ }^{3}$ Abbassia Fever Hospital, Cairo, Egypt.
}

Corresponding Author Amira Mahmoud Al Balakosy

Mobile: $+201221977455$

E mail: drbalakosy@gmail.co $m$

Key words: Epidemiology, meningitis, updates, Outcome
Background and study aim: Meningitis remains a major public health challenge. Epidemiology of meningitis has greatly changed, our aim is to report updates of epidemiologic aspects of meningitis cases including commonest etiologies \& outcome.

Patients and Methods: This is a retrospective descriptivestudy in which data was retrieved from hospital records of patients older than 18years with an admitting or discharge diagnosis of meningitis presented to Abbassia Fever Hospital in the time period 2006-2017.

Results: A total of 959 patients were admitted to Abbassia Fever Hosiptal with final diagnosis of meningitis /meningioencephalitis in the time period 2006-2017. 61\% aged (24-64 years), males $(64.4 \%)$, more cases were reported in spring (38\%) than other seasons, specifically in April (15\%). Septic meningitis was the commonest etiology of

\section{INTRODUCTION}

Meningitis is a serious inflammatory condition of the meninges, the membranes covering the brain and spinal cord, mostly due to infectious causes [1]. Worldwide meningitis burden remains high causing a major morbidity and mortality [2]. Meningitis can be caused by many different pathogens including viruses and fungi but the highest global burden is seen with bacterial meningitis [2]. Acute meningitis can be divided into a bacterial and viral infections while chronic meningitis that develop over two weeks or more meningitis (66.6\%), followed by viral $(17 \%)$ then tuberculous $(15.6 \%)$ while cryptococcal was the least $(0.6 \%)$. Although the etiologic organism was not isolated in 55.3\%, streptococcus pneumonia was the commonest organism identified in $20 \%$, followed by Neisseria meningitidis (12.3\%) \& Haemophilus influenzae $\quad(3.3 \%) . \quad 78.7 \%$ were completely recovered, $17.6 \%$ died \& $3.6 \%$ had complications on discharge. The highest case fatality rate was in older age $(31.7 \%)$. Patient outcome was significantly related to age $(p<0.001)$, smoking $(\mathrm{p}=0.05)$, residence $(\mathrm{p}<0.001)$, etiology of meningitis $(\mathrm{p}<0.001) \quad \&$ occurrence of complication $(\mathrm{p}<0.001)$.

Conclusion: Septic followed by viral then tuberculous are common causes of community acquired meningitis in patients admitted to Abbassia Fever Hospital. Factors affecting patient outcome are age, residence, etiology of meningitis \& occurrence of complication.

is caused mainly by mycobacteria tuberculosis \& fungal infection [3]. Epidemiology of meningitis has greatly changed regarding the distribution of the causative agents and patients' age group owing to the implementation of different immunization strategies \& antimicrobial treatment that dramatically reduced mortality [4]. Viral rather than bacterial meningitis is the most common form of meningitis in high income countries. Bacterial meningitis has an incidence in developed countries of $0.7-0.9$ per 100,000 , but remains as high as 40 per 100,000 in developing countries [5]. 
In Egypt previous studies demonstrated high morbidity and mortality of bacterial meningitis [6], \& reported it as an endemic disease. Updated studies evaluating epidemiological aspects, different etiologies \& disease outcomes of meningitis and/or meningoencephalitis is crucial to improve disease management \& healthcare facilities, in this study we aimed to report epidemiological aspects of meningitis cases admitted to Abbassia fever hospital in the time period 2006-2017.

\section{PATIENTS \& METHODS}

Study type: Retrospective descriptive study.

\section{Study Population}

Adult patients ( $\geq 18$ years of age) with an admitting or discharge diagnosis of meningitis and/or meningoencephalitis presented to Abbassia Fever Hospital in the time period 20062017

Inclusion criteria: Files of patients older than 18 years with final diagnosis of meningitis.

Exclusion criteria: Files of patients diagnosed as meningitis with incomplete data or files with initial diagnosis of meningitis but was not finally confirmed .

\section{Methods}

Data were retrieved from hospital records and collected in pre prepared sheets. Data collected included date of hospital admission \& discharge, demographic data (age, sex, residence, occupation, marital status, and special habits), history of co-morbidity (diabetes mellitus, hypertension, HIV ), clinical signs \& symptoms, routine laboratory investigations (CBC, Random blood sugar, kidney function tests, liver function tests) . Results of blood culture done to all patients with suspected meningitis at admission according to the national guidelines . CSF analysis results (tension and turbidity), chemistry (Protein/glucose), cytology (total number and differential). Results of CSF Gram stain \& Bacterial culture. CSF PCR for viruses, bacteria \& tuberculosis if available \& done. Tuberculin test if documented in the files $\&$ antituberculous drugs for patients not responding to first line antibiotic regimen (third generation cephalosporin). Patient outcome including recovery, occurrence of complications or death.
Then classification of meningitis cases into septic, viral, tuberculous \& fungal was according to the following criteria [7]:

Septic meningitis: a CSF glucose concentration $<40 \mathrm{mg} / \mathrm{dL}(<2.22 \mathrm{mmol} / \mathrm{L})$, a CSF to serum glucose ratio of $\leq 0.4$, a protein concentration $>200 \mathrm{mg} / \mathrm{dL}$ (>2000 mg/L), and a WBC count above $1000 / \mathrm{microL}$, with a percentage of neutrophils usually greater than 80 percent. Confirmed by culture or PCR

Viral meningitis: CSF has a lymphocytic pleocytosis, normal glucose, moderate elevation of protein, and negative-CSF Gram stain and culture.

TB meningitis: CSF exam reveals a lymphocyte predominant pleocytosis with elevated protein and decreased glucose or confirmed by PCR, positive tuberculin test, associated polumonary $\mathrm{T}, \mathrm{B}$ Or improvement on empirical antituberculous treatment .

Fungal meningitis: in patients with risk factors for fungal disease (immunocompromised). CSF showing low glucose levels and elevated protein levels. Inflammatory cell counts have a lymphocytic predominance or confirmed by culture.

\section{Statistical analysis:}

- Analysis of data was done using SPSS (statistical program for social science version 12) program version 23.

- Quantitative data were presented as mean, and SD.

- Qualitative data were presented as number and percentage.

- Chi-square test was used to compare qualitative data between different groups.

- $\mathrm{P}$ value <0.05 was considered statistically significant.

\section{RESULTS}

This is a retrospective study that included 959 patients diagnosed with meningitis and/or meningoencephalitis admitted to Abbassia fever hospital in the time period 2006-2017.

In this study adults aged (24-64 years) were the most affected group (61\%), they were 
predominately males $(64.4 \%)$, \& lived in urban areas (Cairo) (60.1\%). (Table1).

Seasonal distribution showed that more cases were reported in spring (38\%) than other seasons, specifically in April (15\%) \& March (12\%) Figures (1 \&2).

Clinically fever was the commonest symptom recorded in $89 \%$ of the patients. Common signs were neck rigidity, Kering's sign \& Brudzinski sign recorded in $66 \%, 60 \%$ \& $40 \%$ of included patients respectively. While $18.6 \% \& 30.4 \%$ of the patients had convulsions $\&$ disturbed level of consciousness at presentation which were significantly related to intensive care admission $(\mathrm{p}=0.001)$.

Lumbar puncture \& CSF analysis were done to all patients . CSF gram stain \& culture were done in $99 \%$ of patients (Table 2) while CSF PCR (strept.pneumonia, N.meningitidis, , H.influenza , viruses ,T.B \& cryptococcus) was done in only $6 \%$. Collectively using CSF gram stain, culture \& PCR, commonest organism isolated was streptococcus pneumonia $20 \%$ while in 55\% no organism could be identified (Table3). Septic meningitis was the commonest final diagnosis $(66.6 \%)$, followed by viral (17\%) then tuberculous (15.6\%) while cryptococcal was the least $(0.6 \%)$ (Table 4). In this study the final diagnosis of 150 cases was T.B meningitis, the diagnosis of T.B depended on CSF Chemical analysis \& improvement on antituberculous drugs in most cases (106), positive tuberculin test (11 cases ), positive PCR for T.B (21 cases) or associated polumonary T.B (5 cases) \& T.B spine (Potts disease 1 case). Fungal meningitis was diagnosed in 6 cases based on gram positive budding in one case, while the remaining 5 cases were HIV positive with CSF analysis consistent with fungal etiology \& negative culture

Most of the patients complelety recovered (78.7\%) while $3.6 \%$ had complications on discharge (Table 5). Neurological complications were the commonest including motor weakness, convlusions, brain infarction, brain insult, involuntary movement, \& psychosis followed by ENT complications including deafness (8 cases) $\&$ otitis media, less common complications were renal impairement (2 cases), drug induced hepatic injury ( 2 cases), bed sores \& venous ulcers.

Patient outcome was significantly related to age $(\mathrm{p}<0.001), \quad$ smoking $\quad(\mathrm{p}=0.05), \quad$ residence $(\mathrm{p}<0.001)$, final diagnosis $(\mathrm{p}<0.001)$ and occurrence of complications $(p<0.001)$ (Table 6). The mean age of patients who died was $(41 \pm 16)$ significantly older than those who recovered (35 \pm 15.8$)$. Cryptococcal meningitis as a final diagnosis recorded the highest mortality $(100 \%)$, followed by septic (22.4\%) (Table 6). On the other hand highest cure rate was recorded when no organism could be isolated (Fig 3). 
Table (1): Demographic data of the studied group.

\begin{tabular}{|c|c|c|c|}
\hline & & $\mathbf{N}$ & $\%$ \\
\hline \multirow{3}{*}{ Age groups } & Adolesecents(18-24 years) & 313 & $32.6 \%$ \\
\hline & Adults (25-64 years) & 583 & $60.8 \%$ \\
\hline & Elderly ( $\geq 65$ years) & 63 & $6.6 \%$ \\
\hline \multirow{3}{*}{ Sex } & male & 618 & $64.4 \%$ \\
\hline & female & 341 & $35.6 \%$ \\
\hline & Total & 959 & $100.0 \%$ \\
\hline \multirow{3}{*}{ marital status } & single & 485 & $50.6 \%$ \\
\hline & married & 474 & $49.4 \%$ \\
\hline & Total & 959 & $100.0 \%$ \\
\hline \multirow{3}{*}{ *Co-morbidity } & No & 815 & $85.0 \%$ \\
\hline & Yes & 144 & $15.0 \%$ \\
\hline & Total & 959 & $100.0 \%$ \\
\hline \multirow{5}{*}{ Residence } & Cairo & 576 & $60.1 \%$ \\
\hline & Giza & 105 & $10.9 \%$ \\
\hline & Kalyopia & 128 & $13.3 \%$ \\
\hline & Other Governorates & 150 & $15.6 \%$ \\
\hline & Total & 959 & $100.0 \%$ \\
\hline \multirow{3}{*}{ Smoking } & No & 564 & $58.8 \%$ \\
\hline & Yes & 395 & $41.2 \%$ \\
\hline & Total & 959 & $100.0 \%$ \\
\hline \multirow{6}{*}{ Occupation } & unemployed & 210 & $22 \%$ \\
\hline & employee & 135 & $14 \%$ \\
\hline & manual worker & 291 & $30.3 \%$ \\
\hline & student & 184 & $19 \%$ \\
\hline & housewife & 139 & $14.5 \%$ \\
\hline & Total & 959 & $100 \%$ \\
\hline
\end{tabular}

*Diabetes Mellitus, old stroke, ischemic heart disease, HIV or autoimmune disease

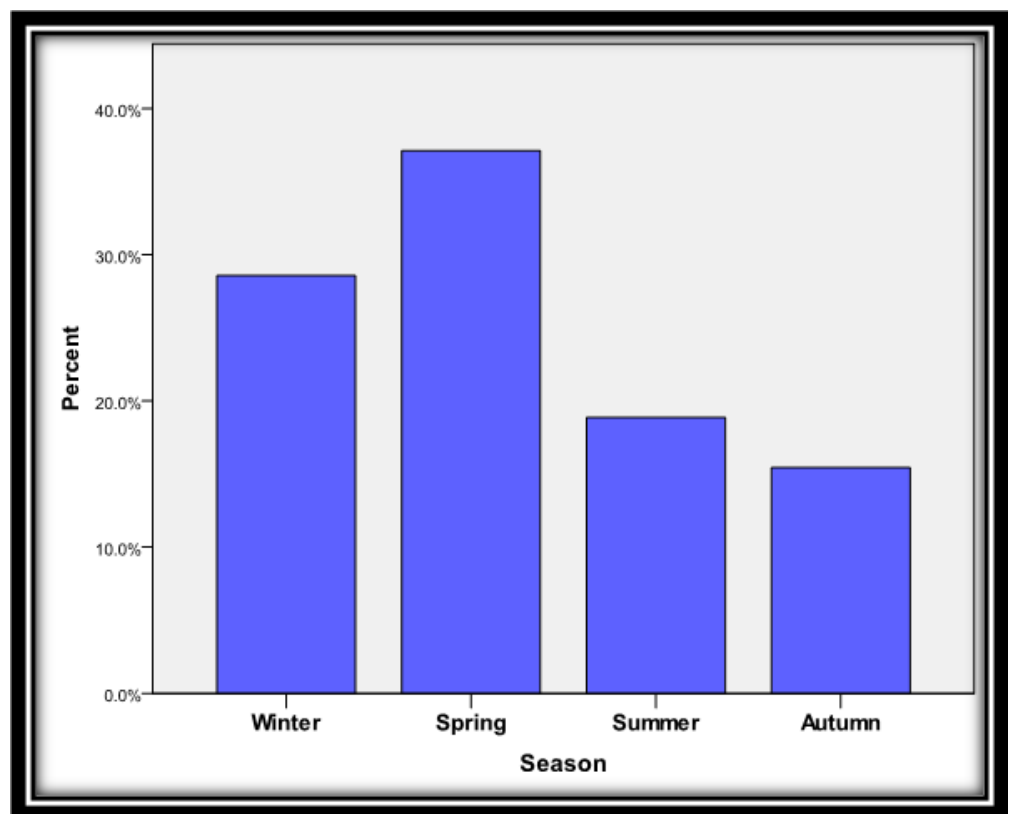

Figure (1) Seasonal distribution of meningitis cases

Ibrahim et al., Afro-Egypt J Infect Endem Dis 2020;10(4):379-388

https://aeji.journals.ekb.eg/

http://mis.zu.edu.eg/ajied/home.aspx 


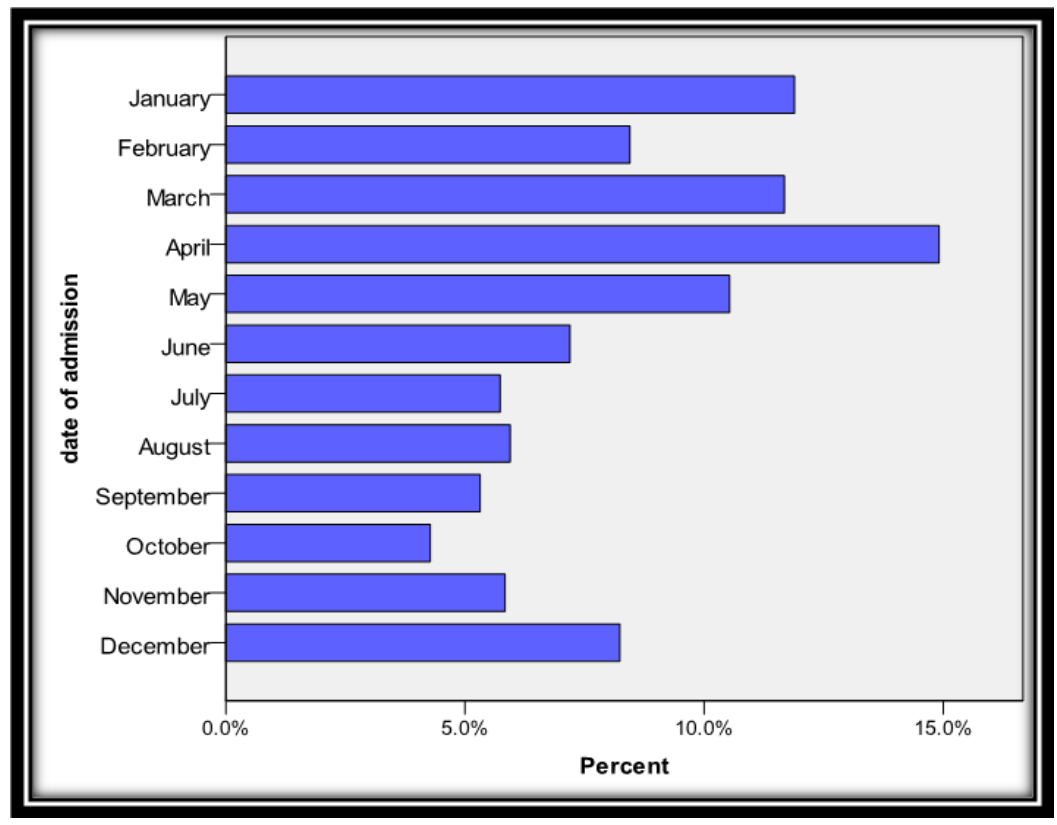

Figure(2): Seasonal distribution of meningitis cases by months

Table (2): CSF film and bacterial culture.

\begin{tabular}{|c|c|c|c|}
\hline & & $\mathbf{N}$ & $\%$ \\
\hline \multirow{10}{*}{ CSF Film } & no organism & 750 & $80.1 \%$ \\
\hline & Strept.Pneumoniae & 94 & $10.0 \%$ \\
\hline & Neisseria Meningitidis & 50 & $5.3 \%$ \\
\hline & Haemophylus Influenza & 2 & $0.2 \%$ \\
\hline & Staph.Aureus & 2 & $0.2 \%$ \\
\hline & Gram-ve bacilli & 34 & $3.6 \%$ \\
\hline & Strept.Pyogens & 1 & $0.1 \%$ \\
\hline & Anaerobic.Bacteria & 2 & $0.2 \%$ \\
\hline & CryptoCoccus (Gram+ve Budding) & 1 & $0.1 \%$ \\
\hline & Total & 936 & $100.0 \%$ \\
\hline \multirow{14}{*}{ CSF culture } & no organism & 578 & $62.0 \%$ \\
\hline & Strept. pneumoniae & 174 & $18.7 \%$ \\
\hline & Neisseria Meningitidis & 101 & $10.8 \%$ \\
\hline & Haemophylus Influenza & 50 & $5.4 \%$ \\
\hline & Staph.Aureus & 4 & $0.4 \%$ \\
\hline & MRSA & 2 & $0.2 \%$ \\
\hline & Listeria & 4 & $0.4 \%$ \\
\hline & Strept.Pyogens & 1 & $0.1 \%$ \\
\hline & Klebsiella & 7 & $0.8 \%$ \\
\hline & E.Coli & 7 & $0.8 \%$ \\
\hline & Acinetobacter & 2 & $0.2 \%$ \\
\hline & $\begin{array}{c}\text { Staph.Coagulase -ve } \\
\end{array}$ & 1 & $0.1 \%$ \\
\hline & CryptoCoccus(Gram+ve Budding) & 1 & $0.1 \%$ \\
\hline & Total & 932 & $100.0 \%$ \\
\hline
\end{tabular}


Table (3): Etiologic organisms isolated by CSF gram stain, culture \& PCR.

\begin{tabular}{|c|c|c|}
\hline & Frequency & Valid Percent (\%0 \\
\hline no organism & 522 & 55 \\
\hline Strept.Pneumoni & 189 & 20 \\
\hline Niesseria Meningitidis & 116 & 12.3 \\
\hline Heamophylus Influenza & 31 & 3.3 \\
\hline Staph.Aureus & 4 & 0.4 \\
\hline MRSA & 3 & 0.3 \\
\hline Listeria & 2 & 0.2 \\
\hline Strept.Pyogens & 1 & 0.1 \\
\hline Klepsiella & 2 & 0.2 \\
\hline E.Coli & 7 & 0.7 \\
\hline Actinobacter & 1 & 0.1 \\
\hline Staph.Coagulase -ve & 2 & 0.2 \\
\hline CryptoCoccus(Gram+ve Budding) & 1 & 0.1 \\
\hline MycoBacterium TB & 8 & 0.8 \\
\hline mixed & 55 & 5.8 \\
\hline Total & 944 & 100.0 \\
\hline
\end{tabular}

Table (4): Final Diagnosis of meningitis cases.

\begin{tabular}{|c|c|c|}
\hline & N & \% \\
\hline Septic & 639 & $66.6 \%$ \\
\hline Viral & 164 & $17 \%$ \\
\hline Tuberculous & 150 & $15.6 \%$ \\
\hline Cryptococcal & 6 & $0.6 \%$ \\
\hline Total & 959 & $100.0 \%$ \\
\hline
\end{tabular}

Table (5): Patient Outcome.

\begin{tabular}{|c|c|c|}
\hline & $\mathbf{N}$ & \% \\
\hline discharged with no complications & 755 & $78.7 \%$ \\
\hline Died & 169 & $17.6 \%$ \\
\hline discharged with complications & 35 & $3.6 \%$ \\
\hline Total & 959 & $100.0 \%$ \\
\hline
\end{tabular}


Table (6): Factors affecting outcome.

\begin{tabular}{|c|c|c|c|c|c|c|c|}
\hline & & \multicolumn{2}{|c|}{ Died } & \multicolumn{2}{|c|}{$\begin{array}{c}\text { Recovered (with or without } \\
\text { complications) }\end{array}$} & \multirow[t]{2}{*}{$\mathbf{t}^{*}$} & \multirow[t]{2}{*}{$P$ value } \\
\hline & & Mean & SD & Mean & SD & & \\
\hline \multirow{2}{*}{\multicolumn{2}{|c|}{ Age }} & 41 & 16 & 35 & 15.8 & 4.62 & $<0.001$ \\
\hline & & $\mathbf{N}$ & $\%$ & $\mathbf{N}$ & $\%$ & $\mathbf{X}^{2^{* *}}$ & P value \\
\hline \multirow{2}{*}{ Sex } & male & 104 & $16.8 \%$ & 514 & $83.2 \%$ & \multirow{2}{*}{0.76} & \multirow{2}{*}{0.39} \\
\hline & female & 65 & $19.1 \%$ & 276 & $80.9 \%$ & & \\
\hline \multirow{2}{*}{ Smoking } & no & 88 & $15.6 \%$ & 476 & $84.4 \%$ & \multirow{2}{*}{3.85} & \multirow{2}{*}{0.05} \\
\hline & yes & 81 & $20.5 \%$ & 314 & $79.5 \%$ & & \\
\hline \multirow{2}{*}{ Co-morbidity } & No & 142 & $17.4 \%$ & 673 & $82.6 \%$ & \multirow{2}{*}{0.15} & \multirow{2}{*}{0.70} \\
\hline & Yes & 27 & $18.8 \%$ & 117 & $81.3 \%$ & & \\
\hline \multirow{4}{*}{ Residence } & Cairo & 89 & $15.5 \%$ & 487 & $84.5 \%$ & \multirow{4}{*}{8.39} & \multirow{4}{*}{0.04} \\
\hline & Giza & 28 & $26.7 \%$ & 77 & $73.3 \%$ & & \\
\hline & Kalyopia & 22 & $17.2 \%$ & 106 & $82.8 \%$ & & \\
\hline & $\begin{array}{c}\text { Other } \\
\text { Govern. }\end{array}$ & 30 & $20.0 \%$ & 120 & $80.0 \%$ & & \\
\hline \multirow{4}{*}{ Diagnosis } & Septic & 143 & $22.4 \%$ & 496 & $77.6 \%$ & \multirow{4}{*}{65.61} & \multirow{4}{*}{$<0.001$} \\
\hline & viral & 12 & $7.3 \%$ & 152 & $92.7 \%$ & & \\
\hline & Tuberculous & 8 & $5.3 \%$ & 142 & $94.7 \%$ & & \\
\hline & cryptococcal & 6 & $100.0 \%$ & 0 & $0.0 \%$ & & \\
\hline \multirow{5}{*}{ occupation } & unempolyed & 35 & $16.7 \%$ & 175 & $83.3 \%$ & \multirow{5}{*}{5.48} & \multirow{5}{*}{0.24} \\
\hline & employee & 24 & $17.8 \%$ & 111 & $82.2 \%$ & & \\
\hline & worker & 59 & $20.3 \%$ & 232 & $79.7 \%$ & & \\
\hline & student & 23 & $12.5 \%$ & 161 & $87.5 \%$ & & \\
\hline & housewife & 28 & $20 \%$ & 111 & $79.9 \%$ & & \\
\hline \multirow{2}{*}{ Complications } & No & 4 & $0.5 \%$ & 755 & $99.5 \%$ & \multirow{2}{*}{732.69} & \multirow{2}{*}{$<0.001$} \\
\hline & Yes & 165 & $82.5 \%$ & 35 & $17.5 \%$ & & \\
\hline
\end{tabular}

*Student t test

**Chi square test 


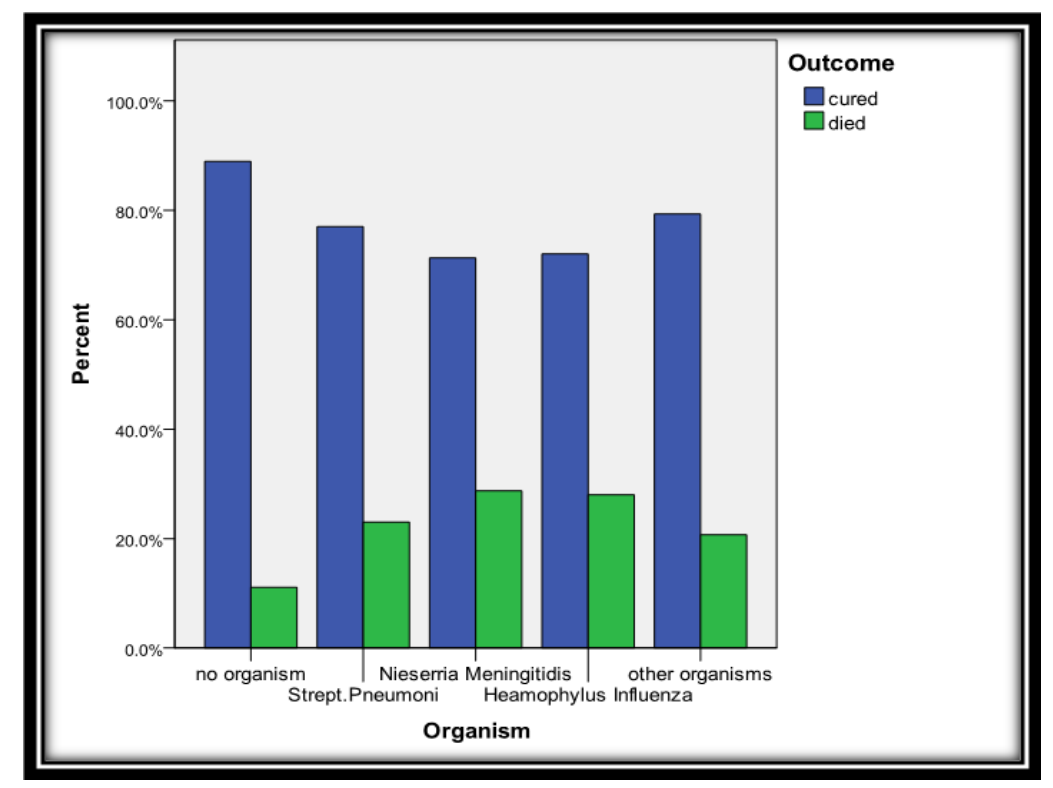

Figure (3): Outcome according to organism

\section{DISCUSSION}

Meningitis remains a major public health challenge. WHO adopted global strategy to defeat meningitis by 2030 [2]. Updated national epidemiological studies are of utmost importance to evaluate the current situation \& decide proper interventions.

Two large epidemiological studies were done in Egypt, first done by Girgis et al. [8] at the time period from 1966 to 1989 in Abbassia Fever Hospital \& the second study by Afifi et al. [6] that was a laboratory based surviellence of bacterial meningitis patients done in 6 infectious disease hospitals in Egypt during the time period of 1998-2004.

Girgis et al., revealed that the commonest etiology of meningitis was Neisseria meningitidis (mostly group A) diagnosed in $27.3 \%$ of the patients, followed by Mycobacterium tuberculosis in $19.7 \%$, Streptococcus pneumoniae in $7.3 \%$, and Haemophilus influenzae in $4.1 \%$ while $27 \%$ of the cases had purulent meningitis but without detectable etiology. Afifi et al., reported that $42 \%$ of included patients were positive for Streptococcus pneumonia, 20\% for Haemophilus influenzae serotype b, $17 \%$ for each of Neisseria meningitidis and Mycobacterium tuberculosis, and $6 \%$ for other bacteria.

In comparison to the above 2 studies, the results of the current study revealed, septic meningitis is the commonest type of meningitis as it represented $(66.6 \%)$ of our patients, followed by viral $(17 \%)$ then tuberculous $(15.6 \%)$ while cryptococcal was the least $(0.6 \%)$.

As regards to causative organisms of septic meningitis our study revealed that streptococcus pneumonia was the commonest organism identified in $20 \%$, followed by Neisseria meningitidis (12.3\%) \& Haemophilus influenzae $(3.3 \%)$, which confirms the changing pattern of the causative organisms of septic meningitis, as our study showed that streptococcus pneumonia now became the principle pathogen instead of Neisseria meningitides in period of 1966 to 1989(8). Also Afifi et al study (6) during 1998-2004 showed that the second commonest pathogen was Haemophilus influenzae serotype b, but in the current study Haemophilus influenza represented only $3.3 \%$ \& N.meningitis was the second common pathogen, this is could be explained by the introduction of highly effective conjugate vaccine of haemophilus influenza [9].

Tuberculous meningitis was revealed in (15.6\%) of our cases, which represent a mild decrease when compared to $19.7 \%$ in the time period 1966 -1989 (8) \& $17 \%$ in the period of 1998-2004 (6), which prove that T.B still represent a big health burden in Egypt.

Etiology of meningitis varies according to geographical distribution, whereas bacterial meningitis is commonest in Africa \& developing countries, viral etiology is more prevalent in developed countries, a large epidemiological 
study done in the United states in the period 2011-2014 [10], showed that enterovirus was responsible for $51 \%$ of the cases, while bacterial meningitis represented only $14 \%$. Our study recorded viral meningitis only in $17 \%$ of the cases.

In the current study meningitis cases were more prevalent among males which agree with the previous Egyptian studies, as males to females ratio was 1.6:1 in the period of 1966-1989 (8), \& males represented the majority of cases among all etiologic pathogens of bacterial meningitis during 1998-2004 (6).

Girgis et al. [8] showed that the percentage of adolescents with the age of 11.7 and 16.5 years was highest among all pathogens, while Afifi et al. [6] showed that commonest pathogen in the young adults (aged 23 years) was T.B , our study included all adult patients older than 18 years with the final diagnosis of meningitis including different etiologic pathogens, \& it was found that the age group 24-64 years were most affected.

In this study seasonal distribution showed that more cases were revealed in spring (38\%) than winter, while Girgis et al [8] showed that most cases occurred in winter, the difference might be due to change in the commonest pathogen in both studies.

In the present study patient outcome was significantly related to age, smoking, residence in rural areas \& final diagnosis. These goes with Afifi et al. [6] who showed that case fatility rate was relatively higher among patients $>40$ years of age and residence in rural areas, in our study patients who died were older than $(41 \pm 16)$ those who recovered $(35 \pm 15.8)$ which was statistically significant, this also agrees with the results of a study about prognostic factors \& determinants of fatal outcome of meningitis [11], in which the risk of death was higher for patients over 44 years of age, and living in areas where infectious diseases services were deficient was also associated with higher death rate (11), these findings agree with our study in which Giza district had the highest case fatality rate, which might be due to the longer distance between this area and Abbassia fever hospital leading to delayed management of the patients.

Regarding etiology, the results of the current study partially agree with the recent worldwide reports, as it was observed that global mortality decreased the most for meningococcal meningitis between 1990 and $2016 \&$ the proportion of meningitis deaths due to Listeria, Staphylococcus, Gram-negative bacteria, fungal, and viral infections increased by 2016 [1]. In the current study, all patients diagnosed as cryptococcal meningitis died, (mortality 100\%). While septic meningitis was associated with case fatality rate of $22 \%, \&$ the commonest associated organism was with N. meningitides, this alarm us that $\mathrm{N}$. meningitides is still a lethal disease in Egypt which agree Afifi et al. [6] who showed that the case fatality rate with $\mathrm{N}$. meningitides was $14 \%$. Given the high case fatality rate of fungal meningitis, local clinical guidelines should be implemented to rapidly identify, diagnose \& start proper antifungal treatment promptly for suspected cases as it usually presents atypically without fever or neck stiffness [12] in high risk patients, in this study most of patients with final diagnosis of fungal meningitis were HIV positive \& presented with fever only.

In the current study gender didn't affect the outcome although male sex was found to be an independent risk factor for adverse outcome in community acquired bacterial meningitis by other studies [13], this difference may be because our study included different etiologies of meningitis not only bacterial

Limitations to the current study is that we depended on records for data collection, \& no organism could be isolated in $55 \%$ of the cases therefore final diagnosis besides organism isolation, depended on clinical presentation, CSF analysis \& prognosis. We conclude that implementation of new diagnostic methods is crucial to improve pathogen identification \& thereby aid to plan appropriate management \& treatment guidelines.

\section{Acknowledgement: None}

Ethical Consideration; Approved from Research Ethical Committee at Ain, Faculty of Medicine, Ain Shams University.

Funding; No Funding was received.

Conflicts of interest: No conflicts of Interest.

\section{REFERENCES}

1. Zunt JR, Kassebaum NJ, Blake N, Glennie L, Wright C, Nichols E, et al. Global, regional, and national burden of meningitis, 1990-2016: a systematic analysis for the Global Burden of 
Disease Study 2016. Lancet Neurol 2018; 17(12):1061-1082.

2. Meningitis-World Health Organization: www.who.int > Health topics

3. Roos KL, Tyler KL. Meningitis, Encephalitis, Brain Abscess, And Empyema. In: Kasper DL \& Fauci AS, editor, Harrison's Infectious Diseases. Third Edition: USA, McGraw Hill Education; 2017. p. 330-76.

4. Brouwer MC, Tunkel AR, Van de Beek D. Epidemiology, diagnosis, and antimicrobial treatment of acute bacterial meningitis. Clin Microbiol Rev 2010; 23(3): 467-492.

5. Brouwer M, Beek Dv. Epidemiology of community-acquired bacterial meningitis. Current Opinion in Infectious Diseases 2018; 31(1):78-84:

6. Afifi S, Wasfy MO, Azab MA, Youssef FG, Pimentel G , Graham TW, et al. Laboratorybased surveillance of patients with bacterial meningitis in Egypt (1998-2004). Eur J Clin Microbiol Infect Dis 2007; 26(5):331-340.

7. Bahr NC, Boulware DR. Methods of rapid diagnosis for the etiology of meningitis in adults. Biomark Med 2014; 8(9): 1085-1103.

8. Girgis NI, Sippel JE, Kilpatrick ME, Sanborn WR, Mikhail IA, Cross E, et al. Meningitis and encephalitis at the Abbassia Fever Hospital,
Cairo, Egypt, from 1966 to 1989. Am J Trop Med Hyg 1993; 48(1): 97-107.

9. Laval CA, Pimenta FC, de Andrade JG, Andrade SS, de Andrade AL. Progress towards meningitis prevention in the conjugate vaccines era. Braz $J$ Infect Dis 2003; 7(5): 315-32.

10. Hasbun R, Rosenthal N, Balada-Llasat JM, Chung J, Duff S, Bozzette SB, et al. Epidemiology of Meningitis and Encephalitis in the United States, 2011-2014. Clin Infect Dis 2017; 65(3): 359-363.

11. Faustini A, Arca' M, Fusco D, Perucci CA. Prognostic factors and determinants of fatal outcome due to bacterial meningitis in the Lazio region of Italy, 1996-2000. Int J Infect Dis 2007; 11(2): 137-144.

12. Michael S. Saag, Richard J. Graybill, Robert A. Larsen, et al. Practice Guidelines for the Management of Cryptococcal Disease, Clinical Infectious Diseases 2000; (30):710-718.

13. Dias SP, Brouwer MC, Bijlsma MW, van der Ende A, van de Beek D. Sex-based differences in adults with community-acquired bacterial meningitis: a prospective cohort study. Clin Microbiol Infect 2017; 23(2): 121.e9-121.e15. 